\title{
Voluntary Tipping and the Selective Attraction and Retention of Service Workers in the United States: An Application of the ASA Model
}

\author{
Michael Lynn, Robert J. Kwortnik Jr., and Michael C. Sturman \\ School of Hotel Administration, Cornell University, Ithaca, NY 14853-6902
}

International Journal of Human Resources Management (forthcoming)

Michael Lynn is Professor of Consumer Behavior (e-mail: wml3@cornell.edu), Robert Kwortnik is Associate Professor of Marketing (e-mail: rjk34@cornell.edu), and Michael C. Sturman is the Kenneth and Marjorie Blanchard Professor of Human Resources (e-mail: mcs5@cornell.edu) at the School of Hotel Administration, Cornell University, Ithaca, NY 14853-6902.

Keywords: Tipping, compensation, selection, retention 


\begin{abstract}
Gratuities paid by consumers are widely used to compensate workers in the service industry despite the fact that this practice permits and even encourages a variety of negative practices - from customer-employee collusion against the interests of the firm to service discrimination against consumers thought to be poor tippers. Such negative effects of tipping raise a question about why it exists — what benefits (if any) do firms receive from tipping to justify this practice? One common explanation for tipping is that it is the most efficient way to provide service workers with performance-contingent rewards and to motivate them to deliver good service. In this paper, we draw upon the Attraction-Selection-Attrition (ASA) Model to describe and test another benefit to firms of this practice, namely that it helps to selectively attract and retain better service workers. Data from a survey of restaurant servers supports this selection effect. Concluding discussion calls for more research on this interesting and understudied form of employee compensation.
\end{abstract}




\section{Voluntary Tipping and the Selective Attraction and Retention of Service Workers in the United States: An Application of the ASA Model}

Although most companies fully control the compensation of their employees, many service firms around the world allow consumers to directly reward staff via the institution of tipping. Among those workers commonly tipped are bartenders, casino croupiers, concierges, delivery drivers, doormen, exotic dancers, hair cutters, maitre’ds, musicians, parking valets, porters, taxicab drivers, tour guides, and waiters/waitresses (Star 1988). The amount given by a single customer to any one worker is typically modest, but the sum of all tips to a given employee often exceeds forty percent of his or her total compensation (Payscale 2009). Furthermore, the amount tipped to all workers is substantial, with one estimate placing annual tips in the United States and Canada alone at over $\$ 40$ billion (Azar 2008). Yet despite the prevalence and magnitude of tipping, the human resource literature has largely ignored this component of compensation. This is a notable gap, not only because of tipping's importance to the ever-growing service sector, but because the characteristics of tipping make it distinct from other forms of compensation, and carry with it important advantages and disadvantages that can have a variety of effects on individual and organizational performance (e.g., Kwortnik, Lynn, and Ross 2009; Lynn and Simons, 2000; Lynn, 2002; Lynn and Withiam, 2008).

From an organizational behavior and human resources perspective, the practice of having customers directly compensate employees is fraught with risks. First, by its very nature, the practice of tipping puts compensation decisions into the hands of customers, which removes from the company's command what is in most other businesses and industries a key factor to 
help attract, motivate, and control employees. Under tipping, employees become agents of the customer as well as of the firm. At best this creates role conflict as employees juggle the competing demands of customers and managers (Eddleston, Kidder, and Litzky 2002). At worst, it leads to collusion between customers and employees against the interest of the firm. For example, bartenders may double pour drinks at no extra charge to the customer in an effort to garner larger tips. Second, as a form of pay-for-performance, tipping encourages employees to devote energy to tasks that they perceive will get them greater returns. As such, compensation via tips motivates employees to discriminate against customers perceived to be poor tippers, which can lead to lawsuits and the loss of business from those customers discriminated against (Lynn 2004). Third, tipping results in variable and uncertain incomes (Butler and Skipper 1980). This uncertainly is likely to attract a younger, part-time, and less professional workforce (Parise 1987). Fourth, tipped compensation increases the firm's risk of non-compliance with employment-tax obligations and associated fines and penalties, because tip income is easy for employees to hide (Lynn and Withiam 2008). In fact, the United States Internal Revenue Service estimates that half of all tip income is undeclared —making it the most under-reported source of legal income (Internal Revenue Service 1990). Finally, tipping opens firms up to potential employment discrimination lawsuits. Because tipping is an unnecessary business practice (i.e., business could compensate employees in ways that do not include voluntary tipping) that at least sometimes results in Black employees receiving lower pay than White employees doing comparable work (Ayres, Vars, and Zakariya 2005; Lynn, Sturman, Ganley, Adams, Douglas, and McNeil 2008), the company may be responsible for resultant pay discrimination, even though it is the customers who are making the discriminatory pay decisions. 
These potential negative effects of tipping policies raise a question about why tipping exists. What potential benefits to firms could tipping provide that might outweigh the negative effects and thereby explain the pervasiveness of this practice in the service industry? One common answer to this question is that tipping is a performance-contingent reward system that motivates workers to deliver better service. As such, consistent with the precepts of agency theory (Jensen and Meckling 1976), the practice of voluntary tipping provides a mechanism to align employees’ and their organization's interests.

Agency theory is based on the premise that what is best for the principal (e.g., the company) is not necessarily best for the agent (e.g., the employee). Aligning employees’ and employers’ interests, such as through a compensation system, can help ensure that employees will exhibit the sorts of behaviors desired by the organization (Gerhart and Milkovich 1992; Eisenhardt 1989). When employee performance cannot be monitored, agency theory suggests that tying employee compensation to desired organizational outcomes will keep employees’ and the company’s interests aligned. Service firms generally want employees to deliver good service, but the intangible and customized nature of certain services makes it difficult for firms to monitor and reward employee efforts. In many service contexts (e.g., restaurant dining, spa services, hair styling), customers are often in a better position than firms to know what they want in the way of service and how well a service worker performs. This means customers can often monitor service-employee behavior and reward outcomes much more efficiently than can firms (Azar 2004; Ben-Zion and Karni 1977; Jacob and Page 1980; Kwortnik, Lynn, and Ross 2009), so service firms leave these tasks to their customers via the institution of tipping. 
From an economic perspective, tipping is an efficient reward mechanism because tips provide service workers with a financial incentive to work hard and deliver good service (Azar 2004; Lynn and McCall 2000). This economic argument may seem obvious, but Lynn and others (Azar 2008; Lynn 2003; Schwartz 1997) have questioned the incentive effect of tipping because the correlation between customer ratings of service and the tips they offer is quite small and may not be evident to servers (see Lynn 2001). From an expectancy theory perspective (Vroom 1964), the motivating effects of tipping will be limited if employees do not think that providing better customer service will result in larger tips. Fortunately, recent research has addressed this issue and found that servers do, on average, perceive the tips they receive to be affected by the service they provide, though the strength of this perceived relationship varies across individuals (Kwortnik, Lynn, and Ross 2009). Moreover, that research found that tipping does indeed motivate servers to deliver better service

In this paper, we suggest and test another potential benefit to firms of tipping that goes beyond its agency-theoretic role as a mechanism aligning employee interests (i.e., compensation) with organizational interests (i.e., the provision of good customer service). A tipping policy may also serve as a signaling device for the types of employees a company wants to hire, and may help retain those employees who fit this profile and who feel they benefit from the policy. That is, a tipping policy may play a role, much like the process described by the Attraction-SelectionAttrition (ASA) model (Schneider 1987), in influencing the types of workers who seek jobs and who choose to remain in the service industry. 


\section{ASA Model and Tipping Policy}

The ASA model (Schneider 1987) is a person-based model of the organization that conceptualizes the culture of an organization as a reflection of employees' collective personality (Schneider 1987). The model suggests that three processes lead to greater homogeneity in the knowledge, skills and abilities of employees. First, attraction involves the fit between a person’s and an organization's characteristics. Second, selection involves organizations and applicants choosing one another based on how well they meet each other's needs. Third, attrition occurs when employees leave organizations that they do not fit.

Past research has primarily applied the ASA model to understanding personality, socialization, and culture, but there is some research demonstrating its potential for explaining the effects of compensation policies. For example, Cable and Judge (1994) applied the concept of "person-organization fit" to understand the role of compensation in attraction. They showed that "individuals have relatively established pay preferences, and that pay system characteristics other than pay level are important in the job search process” (Cable and Judge 1994, p. 341). Similarly, high-ability workers prefer performance-based reward systems more than do lowability workers (Farh, Griffeth, and Balkin 1991). Research has also shown that compensation can play a role in the attrition process, in that performance-contingent compensation helps firms retain top performing employees and encourages the turnover of low performers (Banker, Lee, Potter, and Srinivasan 2000; Trevor, Gerhart, and Boudreau, 1997; Salamin and Hom 2005; Sturman and Trevor 2001).

While the ASA model has been applied to understanding processes that lead to homogeneity of employees within an organization, we argue that the model also has applicability 
for understanding the characteristics of employees within a profession. The effects of organization practices on employee attraction, selection and retention specified by the ASA model will generalize to occupations when the practices are typical of the occupation. That is, when the members of certain professions are compensated in the same way by the vast majority of employers, the ASA model can be used to understand how this characteristic of the profession influences the sort of individuals attracted to, selected for, and remaining in that profession. Voluntary tipping is common in the U.S. restaurant industry, so any effects of this compensation policy on the attraction and retention of employees will be evident at the occupational rather than the firm level. ${ }^{1}$ Yet as Lynn and Withiam (2008) note, there are few if any empirical tests to see if voluntary tipping policies (or indeed other occupational characteristics) have such effects.

Tipping should selectively attract better service workers because top performers generally like performance-contingent rewards more than do poor performers (Farh, Griffeth, and Balkin 1991). That is, tipping may enhance the recruitment of good workers because good performers can expect to earn larger tips than poor performers (Lynn and Withiam 2008; Schotter 2000). Certainly one characteristic of desirable service workers is a positive attitude toward delivering good service. Such an attitude should lead to better service delivery (Ajzen and Fishbein 1977), so servers with more positive service attitudes should like being compensated through tips more than servers with less positive service attitudes. Moreover, this relationship should be stronger the greater the servers' perceptions of a contingency between tips and service. Thus, we hypothesize:

\footnotetext{
${ }^{1}$ The effects of tipping in attracting and retaining better workers into tipped occupations observed in the United States should be evident at the level of firms when tipping policies vary across employers, as in Europe.
} 
H1: Servers with more positive service attitudes will be more attracted to tipped service jobs than servers with less positive service attitudes.

H2: The positive relationship between service attitudes and attraction to tipped service jobs will be stronger among servers who perceive tips to be contingent on the service they provide than among servers for whom this perception is less strong.

A tipping policy can also help retain better employees for two reasons: fit with employee preferences and the provision of higher compensation. The ASA model purports that employees who fit with the culture of a company will be more likely to remain with that company. Part of this fit involves congruence between employee compensation preferences and organizational practices (Cable and Judge 1994). As such, employees who prefer working for tips will be more likely to remain in jobs that reward in this way. Since restaurants in the United States usually rely on tipping to compensate their servers, congruence between employee preferences for compensation via tipping and tip policy is unlikely to reduce employee switching between restaurants, but it should increase retention in the profession by reducing employee loss to other occupations. Conversely, employees for whom pay preferences and tip policy are incongruent are more likely to leave a company in favor of employment in some other occupation. Hence, we hypothesize:

H3: Servers will stay in tipped occupations longer the more they are attracted to tipped service jobs.

As a consequence of Hypotheses 1 and 3 and consistent with the ASA model, employees with positive service attitudes should stay in tipped jobs longer than those with less positive service attitudes. However, we should also see that the strength of this link is influenced by the 
degree to which workers' service attitudes lead to greater compensation. To the extent that tipping is a reward for good service and servers with more positive service attitudes deliver better service, then workers with more positive service attitudes should receive larger tips than those with less positive service attitudes, and this in turn should increase tenure in the occupation. This view is consistent with the more general research on pay levels and pay for performance. Higher compensation is associated with less job search behaviors (e.g., Bretz, Boudreau, and Judge 1994), lower turnover (e.g., Trevor, Gerhart, and Boudreau 1997), and lower turnover rates (e.g., Leonard 1987; Powell, Montgomery, and Cosgrove 1994). When pay is tied to performance, the probability of turnover among high performers is reduced (Trevor, Gerhart, and Boudreau 1997; Salamin and Hom 2005), while there are additional pressures on poor performers to leave. Similarly, Dreher (1982) asserted that performance-based pay may influence employees' job satisfaction levels and consequently affect their desire to leave the organization. Podsakoff and Williams (1986) also found evidence that the positive relationship between performance and job satisfaction was strengthened when rewards were contingent on performance. We therefore expect:

H4: Servers with more positive service attitudes will receive larger tips.

H5: Servers will stay in tipped occupations longer the higher their income from tips.

H6: Servers with more positive service attitudes will stay in tipped occupations longer than those with less positive service attitudes, and this relationship will be mediated by both attraction to tipped jobs and level of perceived tip income.

These hypotheses are summarized in Figure 1 and tested in the following study. 
Insert Figure About Here

\section{Method}

Sample. Experimenting with tipping policies in real-world restaurants to examine their influence on employee recruitment and retention is not practically feasible. Furthermore, despite the move of some hospitality firms away from tipping (Newman 2007), the practice of tipping is still so widespread within the United States that it is difficult to find naturalistic experiments in which some services adopt tipping while others do not, and even more difficult in those rare cases that can be found to obtain the needed measures of employee competence and turnover. Thus, we relied upon survey data to study these issues. Specifically, we used an online survey of restaurant waiters and waitresses to test the assumed relationships underlying the selective attraction and retention effects of voluntary tipping.

Current and former restaurant servers completed an online survey about their experiences on and opinions of the job. The survey was anonymous, so obtaining written informed consent was unnecessary. We recruited participants by sending invitations, or having invitations sent for us, to current and former students in hospitality programs around the United States and by asking respondents to recruit additional participants from among the restaurant servers they knew, which yielded 435 responses. However, only respondents from the United States, who had worked as a server within the past year, who were the first to respond from their remote IP address, and who provided completed surveys, were retained for analysis. Data from 213 current and 124 recent (within the past year) servers across 43 different states and the District of 
Columbia were analyzed. These servers ranged in age from 16 to 63 with a mean age of 24.6 years. Ninety-one percent of the servers were white, 76 percent were female, and 14 percent were married. These respondents were not representative of the population of servers in the United States, but our goal was to test the relationship between variables and the heterogeneous sample we obtained was adequate for that purpose.

Measures. We measured servers' attitudes toward providing good service with Larsen and Bastiansen’s (1991) Service Attitudes Scale. This scale assesses servers’ self-reported cognitive, affective, and behavioral reactions to various aspects of service work. Among the aspects of service tapped by the scale items are knowing job requirements, empathizing with customers, treating customers politely, learning customers’ individual needs, going beyond normal job requirements and giving customers something extra, and keeping customers informed. This measure had a coefficient alpha of .79.

The other constructs in the selection effects model—servers’ beliefs that tips vary with service delivery, servers' attraction to tipped service jobs, and servers' tenure in tipped positions - were measured with items developed for this study. The perceived service-tip contingency was assessed with a three-item scale (coefficient alpha of .77) measuring servers' beliefs that they could earn larger tips by delivering better service (the items are: "I can substantially increase my tips by providing better service," "The size of my tips is strongly affected by the quality of service I deliver," and "How much clients tip me seems unrelated to the quality of service I give them” (7-point scale: 1 = Strongly disagree, $4=$ Neutral, $7=$ Strongly agree, with the last item reverse coded). Attraction to tipped service jobs was measured with a single-item rating of preference for working at a restaurant with voluntary tipping versus 
for an $18 \%$ automatic gratuity (7-point scale: 1 = Strongly prefer working for voluntary tips, $4=$ No preference, 7 = Strongly prefer working for $18 \%$ automatic gratuity; responses were reverse coded so that larger numbers reflect a stronger attraction to tipped service jobs). Tip income was measured as comparative tips: a single-item rating of how respondents perceived the size of their tips compared to the tips of co-worker servers (7-point scale: 1 = Much larger than most others' tips, 4 = About the same as most others' tips, and 7 = Much smaller than most others' tips; responses were reverse coded for analysis, so that larger numbers reflect larger tips relative to co-workers). ${ }^{2}$ Tenure as a server was measured by years employed as a server at any and all restaurants.

In addition, we collected demographic information to use as control variables. Specifically, respondents indicated their sex (male $=0$, female $=1$ ), year of birth (used to calculate age in years), race (coded white $=0$, not white $=1$ ), and marital status (not married $=0$, married $=1)$.

\section{Results}

Descriptive results. Sample sizes and the means and standard deviations of the variables in this study along with inter-item correlations are presented in Table 1. Of particular note is that the three-item index of perceived service-tip contingency had values ranging from 1.0 to 7.0, with a mean of 5.17 and a standard deviation of 1.47 . Of the mean scores, $74.3 \%$ exceeded 4.0, which reflects a neutral position. This result replicates Kwortnik, Lynn, and Ross’s (2009)

\footnotetext{
${ }^{2}$ A self-report measure of average percent tipped produced effects similar to those of the relative tip ratings but with a weaker relationship to server tenure that was not statistically reliable after controlling for service attitudes and preference for working for tips.
} 
finding that most servers do perceive a moderate-to-strong relationship between the service they provide and the tips they receive in return.

Insert Table 1 About Here

Selective attraction effect. Attraction to tipped service jobs was regressed on the service attitudes scale, the perceived service-tip contingency measure, and their product (interaction) in a hierarchical multiple regression that included server age, sex, race and marital status as covariates or control variables (see Table 2). Service attitudes were significantly and positively related to preference for working for tips $(\mathrm{B}=.40, \mathrm{t}(312)=2.33, \mathrm{p}<.05, \mathrm{r}=.14)$. Consistent with Hypothesis 1, workers with more positive service attitudes preferred working for voluntary tips as opposed to automatic gratuities. Furthermore, the relationship between service attitudes and the attraction to tipped service jobs was moderated by the perceived service-tips contingency as specified in Hypothesis 2: the more that servers believed tips depend on the service they deliver, the stronger the relationship between their service attitudes and their attraction to tipped service jobs (interaction $\mathrm{B}=.24, \mathrm{t}(309)=2.50, \mathrm{p}<.05$, partial $\mathrm{r}=.14$ ). This moderated relationship between service attitudes and attraction to tipped service jobs is easily explained in terms of service attitudes causing increased attraction to tipped service jobs when it leads to expectations of higher tip income but is difficult to explain otherwise. Thus, when taken together, these findings provide empirical support for the idea that tipping selectively attracts 
desirable service workers, at least in the restaurant context (Lynn and Withiam 2009; Schotter 2000).

Insert Table 2 About Here

Selective retention effect. Hypotheses 3 through 5 were assessed in separate regression analyses all of which included server age, sex, race and marital status as covariates (see Table 3). Attraction to tipped service jobs was significantly and positively related to server tenure ( $\mathrm{B}=$ $.28, \mathrm{t}(307)=3.40, \mathrm{p}<.01, \mathrm{r}=.20)$. Service attitudes was significantly and positively related to tip income $(\mathrm{B}=.31, \mathrm{t}(310)=3.58, \mathrm{p}<.001, \mathrm{r}=.21)$. Further, tip income was significantly and positively related to tenure as a server $(\mathrm{B}=.64, \mathrm{t}(305)=3.97, \mathrm{p}<.001, \mathrm{r}=.27)$. Thus, Hypotheses 3 through 5 were supported, suggesting that a voluntary tipping policy also helps to selectively retain service workers with more positive service attitudes.

Insert Table 3 About Here

The mediated relationships predicted in Hypotheses 6 and depicted in Figure 1 were assessed using the regression analyses advocated by Baron and Kenny (1986) (see Table 4). Again, all the regression models included server age, sex, race and marital status as covariates. The service attitudes scale was significantly and positively related to server tenure $(B=.51$, 
$\mathrm{t}(307)=1.97, \mathrm{p}<.05, \mathrm{r}=.13)$ and this relationship was sizably reduced after statistically controlling for tip income and attraction to tipped service jobs $(\mathrm{B}=.25, \mathrm{t}(303)=.99, \mathrm{p}=.32$, partial $r=.06)$. Furthermore, the effects of tip income $(B=.50, t(303)=3.00, p<.01$, partial $r=$ $.17)$ and attraction to tipped service jobs $(\mathrm{B}=.20, \mathrm{t}(303)=2.39, \mathrm{p}<.02$, partial $\mathrm{r}=.14)$ remained significant after controlling for service attitudes. Consistent with Hypothesis 6, these results meet the criteria for mediation and support the mediation effects depicted in Figure 1. That is, service workers with more positive service attitudes will stay in tipped positions longer in part because they have a preference for working for tips and believe they earn comparatively higher tipped incomes than their coworkers.

Insert Table 4 About Here

\section{Discussion}

The ASA model (Schneider 1987) has been used to explain homogeneity in organizations as a result of processes related to employee preferences and attitudes. In this paper, we show this same explanation has merit for understanding individuals' attraction, selection, and attrition to an occupation characterized by a specific form of compensation. The results of this study indicate that workers with positive service attitudes like working for tips more and stay in tipped restaurant service occupations longer than do workers with less positive service attitudes. The relationship between service-attitudes and attraction to tipped service jobs was stronger among those servers who believed that they could substantially increase their tips by delivering good 
service and the relationship between service-attitudes and tenure as a server was mediated by attraction to tipped service jobs and tip income. These results provide empirical support for the idea that tipping helps to selectively attract and retain more desirable service workers. More generally, they suggest that reliance on tipping as a form of employee compensation is an organizational characteristic that influences applicant and employee behavior in a manner consistent with the ASA model (Schneider 1987). The practical implications of these findings along with our research limitations and directions for future research are discussed below.

\section{Practical Implications}

The selection effects of tipping mean that this form of compensation can be used to help solve the problem of adverse selection in employment faced by managers in service industries (Schotter 2000). Service managers often have inadequate information to use for distinguishing good job applicants from bad ones, while prospective employees often have at least somewhat valid knowledge of their own attitudes toward providing good service. By encouraging more competent and motivated workers to self-select into tipped positions, tipping policies can help managers take advantage of this information asymmetry. However, our finding that about thirty percent of the servers in our survey did not believe tips were affected by the quality of the service they provide, together with the finding that service attitudes were a weaker predictor of attraction to tipped service jobs among that group of servers, suggests that tipping policies as a tool for human resource management should be supplemented with inquiries to job applicants about their beliefs concerning the determinants of tip size. Tipping will not selectively attract- 
or motivate for that matter—-those workers who believe tip sizes are largely independent of service quality, so applicants who express such beliefs should be regarded as riskier hires.

Interestingly, many hospitality companies are discarding tipping as a human resource tool by replacing voluntary tipping with automatic service charges or service-inclusive pricing. For example, 40 percent of restaurants in Miami Beach, Florida now apply an automatic service charge to guest checks in lieu of voluntary tipping (Kwortnik, Lynn, and Ross 2009). In the leisure cruise industry, Holland America Line announced in 2004 that the firm would abandon its decades-old "tipping not required" gratuity policy (which was a defacto voluntary tipping policy) in favor of a service charge. In making this change, Holland America joined a growing list of cruise lines that automatically apply a separate charge for service (Engle 2004). Our empirical support for the idea that tipping helps selectively attract and retain workers with more positive service attitudes does not mean that shifting from tipping as a human resources tool is misguided. Tipping is a complex practice with many implications for businesses other than its effects on employee recruitment and retention (see Lynn and Withiam 2009). Thus, other considerations may dictate an abandonment of tipping despite its positive effects on employee recruitment and retention. However, our data do support one argument in favor of voluntary tipping — the selective attraction and retention of more service-oriented workers; therefore, managers should take that argument into account when making decisions about tipping policies.

\section{Limitations}

The data in this study come from cross-sectional surveys of restaurant servers. Thus, they do not permit causal inferences. In particular, reverse causal processes and third factor confounds cannot be definitely ruled out, especially for simple main effects. However, the finding that the 
relationship between service attitude and attraction to tipped service jobs was moderated by perceived service-tip contingency is difficult to explain in terms of reverse causality or confounds. Thus, this interaction effect suggests that service attitudes causally impact attraction to tipped service jobs to the extent that workers believe their service will be rewarded with larger tips. Similarly, the mediation of the relationship between service-attitudes and tenure as a server by attraction to tipped service jobs and tip income is most plausibly and parsimoniously explained as service-attitudes affecting tenure thru its effects on tip income and attraction to tipped service jobs.

Our moderation and mediation results pose difficulties for any alternative explanation, including one based on confounding stemming from common method variance (CMV), but the potential for CMV in our data deserves additional discussion. The prevalence of CMV is hotly debated (c.f., Podsakoff, MacKenzie, Lee, and Podsakoff 2003; Spector 2006) as are the appropriate means of correcting for it (see Richardson, Simmering and Sturman 2009). What is clear is that most of the tests of common method variance "tend to identify CMV when it is not present”; only the confirmatory factor analysis marker approach with an ideal marker identifies CMV with low rates of false positives (Richardson, Simmering, and Sturman 2009). Since we did not have an ideal marker and since correcting for CMV when it is not present reduces the accuracy of estimates of relationships, we did not test or correct for CMV in our data. While without a marker variable it is possible to use the unmeasured latent method construct approach (Williams, Cote, and Buckley 1989), its unreliability as a test makes it an undesirable means to address a CMV concern (Richardson, Simmering, and Sturman 2009). 
More important than potential statistical remedies, there are a prior reasons to believe that our results are not adversely affected by CMV. Although all data is collected from the same survey, the dependent and independent variables we collected were measured with different response scales. Service attitudes and perceived service-tip contingency shared a common response scale, but they were not used to predict one another. Similarly, attraction to tipped service jobs and tip income were measured with similar response scales, but they were not used to predict one another either. This use of different response scales on the different sides of our regression equations significantly reduces the potential for CMV to bias our results. Second, the potential significance of interaction terms are not influenced by CMV. If results were attributable to an underlying method factor, then an interaction would explain no additional variance beyond that captured by the linear effect of any other measure sharing that variance. Similarly, for any analysis with multiple independent variables collected from the same method, CMV would be captured by only one of the independent variables. As most of our models (all but the prediction of tip income) include either a statistically significant interaction or significant multiple independent variables, CMV cannot be the sole reasons for the relationships we detect in our analyses. Nevertheless, it would be valuable for future research on the selection effects of tipping to collect data from multiple sources if possible, or otherwise to include ideal marker variables to help test and control for CMV.

Another limitation of our data is the modest size of the observed correlations of service attitudes with attraction to tipped service jobs and tenure as a server - correlations of .14 and .13 respectively. Nonetheless, we believe these correlations are meaningful for two reasons. First, correlations of .13 and .14 are typical for personality effects on various job performance 
measures (see Barrick, Mount and Judge 2001), so larger effects are not expected. Second, Abelson (1985) has shown that even small effects as measured by percentage of variance explained (i.e., $\mathrm{r}^{2}$ ) have meaningful consequences when accumulated over multiple instances. For example, he found that individual differences in batting skill among professional baseball players accounted for only .003 percent of the variance in whether or not a batter gets a hit in a single at bat. This corresponds to a correlation of only .055, but it produces meaningful individual differences in batting averages across multiple at bat opportunities. Similarly, modest selection effects can have large consequences for organizational performance when aggregated across many employees. When considering the effect of tipping on servers, we are considering an effect that can aggregate over the majority of the restaurant industry in the United States, including hundreds of thousands of establishments and millions of workers (Bureau of Labor Statistics 2009).

\section{Directions for Future Research}

One area of research highlighted by this paper is the extension and application of the ASA model to professions. While the ASA model has led to the hypothesis of greater homogeneity within organizations, the logic seems equally applicable to suggesting greater homogeneity within certain occupations. Examining tipped professions are an interesting first step in this regard, as waiters and waitresses work in a profession that is almost universally characterized (at least presently in the United States) by a specific form of compensation. Our results do suggest that this form of compensation influences individuals' selection, attraction, and attrition from this profession. We would expect, though, that similar hypotheses could be 
generated for other professions. While perhaps compensation policy may play a role in other contexts (e.g., many different sales positions are compensated with commissions), other characteristics of occupations (e.g., type of work performed, stress associated with certain jobs, societal perceptions of certain jobs) may similarly influence the type of people attracted to and retained in these occupations. In other words, the ASA model may help explain employee behaviors at different levels of analysis.

Our research also suggests that further work on the compensation practice of tipping may be a fruitful area for human resource research. Tipping raises many issues of interest to organizational behavior and human resources scholars apart from its selective attraction and retention effects. As previously mentioned, for example, tipping can provide service workers with an incentive to offer more personalized service, but also to discriminate in service delivery to groups of consumers perceived to be poor tippers. Tipping can also increase employee role conflict and employee collusion with consumers against the interests of the firm, lead to underreporting of employee income and associated tax liabilities, and have an adverse impact on the employment compensation of racial minorities. Given these issues of relevance to human resources management, it is surprising that so little research has focused on tipping. Hopefully, this paper will call attention to the topic and will encourage more organizational behavior and human resources scholars to join those in economics (e.g., Bodvarsson and Gibson, 1994; Azar, 2005), hospitality management (e.g., Namasivayam and Upneja, 2007; Tse, 2003), marketing (e.g., Kwortnik, Lynn, and Ross, 2009; Lynn, Zinkhan, and Harris, 1993), and social psychology (e.g., Seiter 2007; Strohmetz, Rind, Fisher, and Lynn 2002) in studying this interesting form of employee compensation. 


\section{References}

Abelson, R.P. (1985), “A Variance Explanation Paradox: When A Little Is A Lot,” Psychological Bulletin, 97, 129-133.

Ajzen, I. and Fishbein, M. (1977), “Attitude-behavior Relations: A Theoretical Analysis and Review of Empirical Research,” Psychological Bulletin, 84, 888-918.

Ayres, I., Vars, F. and Zakariya, N. (2005), “To Insure Prejudice: Racial Disparities In Taxicab Tipping,” Yale Law Journal, 114, 1613-1674.

Azar, O. (2004), “Optimal Monitoring With External Incentives: The Case Of Tipping,” Southern Economic Journal, 71 (1), 170-181.

Azar, O. (2005), “Who Do We Tip and Why? An Empirical Investigation,” Applied Economics, 37, 1871-1879.

Azar, O. (2008), “Incentives and Service Quality in the Restaurant Industry: The TippingService Puzzle,” Applied Economics, 1-11, iFirst.

Banker, R.D., Lee, S.Y., Potter, G. and Srinivasan, D. (1996), “Contextual Analysis of Performance Impacts Of Outcome-Based Incentive Compensation,” Academy of Management Journal, 39, 920-948.

Banker, R.D., Lee, S.Y., Potter, G. and Srinivasan, D. (2000), “An Empirical Analysis of Continuing Improvements Following The Implementation of A Performance-Based Compensation Plan,” Journal of Accounting Economics, 30, 315-350.

Baron, R.M. and Kenny, D.A. (1986), “The Moderator-Mediator Variable Distinction in Social Psychological Research: Conceptual, Strategic, and Statistical Considerations,” Journal of Personality and Social Psychology, 51, 1173-1182. 
Barrick, M.R., Mount, M.K. and Judge, T.A. (2001), "Personality and Performance At The Beginning of The New Millennium: What Do We Know and Where Do We Go Next?,” International Journal of Selection and Assessment, 9, 9-30.

Ben-Zion, U. and Karni, E. (1977), “Tip Payments and Quality of Service,” in O.C. Ashenfelter and W.E. Oates (Eds.), Essays in Labour Market Analysis, New York: John Wiley and Sons, 37-44.

Bodvarsson, O. and Gibson, W. (1994), “Gratuities and Customer Appraisal of Service: Evidence From Minnesota Restaurants,” Journal of Socio-Economics. 23, 287-302.

Bureau of Labor Statistics. (2008). Occupational employment statistics, Department of Labor. SOC code 353031, for the period May 2008, accessed 9/22/09.

Butler, S. and Skipper, J.K. (1980), "Waitressing, Vulnerability and Job Autonomy: The Case of the Risky Tip,” Sociology of Work and Occupations, 7, 487-502.

Cable, D.M. and Judge, T.A. (1994), "Pay Preferences and Job Search Decisions: A PersonOrganization Fit Perspective,” Personnel Psychology, 47, 317-348.

Eddleston, K.A., Kidder, D.L. and Litzky, B.E. (2002), “Who’s the Boss? Contending With Competing Expectations From Customers and Management," Academy of Management Executive, 16, 85-95.

Engle, J. (2004), “Is A Mandatory Gratuity Still A Tip?,” The Ithaca Journal, September 11, 111A.

Farh, J., Griffeth, R.W., and Balkin, D.B. (1991), “Effects of Choice of Pay Plans On Satisfaction, Goal Setting, and Performance,” Journal of Organizational Behavior, 12, 55-62. 
Internal Revenue Service (1990), Tip Income Study, 1530 (8-90), Catalog No. 12482K, Department of the Treasury, Washington, D.C.

Jacob, N. and Page, A. (1980), “Production, Information Costs and Economic Organization: The Buyer Monitoring Case,” American Economic Review, 70, 476-478.

Kwortnik, R.J., Lynn, M. and Ross, W.T. (2009), “Buyer Montitoring: A Means To Insure Personalized Service,” Journal of Marketing Research, XLVI, 573-583.

Larsen, S.and Bastiansen, T. (1991), “Service Attitudes In Hotel and Restaurant Staff and Nurses,” International Journal of Contemporary Hospitality Management, 4, 27-31.

Lynn, M. (2001), “Restaurant Tipping and Service Quality: A Tenuous Relationship,” Cornell Hotel and Restaurant Administration Quarterly, 42, 14-20.

Lynn, M. (2003), “Tip Levels and Service: An Update, Extension and Reconciliation,” Cornell Hotel and Restaurant Administration Quarterly, 44, 139-148.

Lynn, M. (2004), “Ethnic Differences In Tipping: A Matter of Familiarity With Tipping Norms,” Cornell Hotel and Restaurant Administration Quarterly, 45, 12-22.

Lynn, M. (2005), “Increasing Servers’ Tips: What Managers Can Do and Why They Should Do It,” Journal of Foodservice Business Research, 8, 89-98.

Lynn, M. and McCall, M. (2000), “Gratitude and Gratuity: A Meta-Analysis of Research on the Service-Tipping Relationship,” Journal of Socio-Economics, 29, 203-214.

Lynn, M. and Simons, T. (2000), “Predictors of Male and Female Servers’ Average Tip Earnings,” Journal of Applied Social Psychology, 30, 241-252. 
Lynn, M., Sturman, M., Ganley, C., Adams, E. Douglas, M. and McNeil, J. (2008), “Consumer Racial Discrimination in Tipping: A Replication and Extension,” Journal of Applied Social Psycyhology, 38, 1045-1060.

Lynn, M. and Withiam, G. (2008), “Tipping and Its Alternatives: Business Considerations and Directions for Research,” Journal of Services Marketing, 22(4), 328-336.

Lynn, M., Zinkhan, G. and Harris, J. (1993), “Consumer Tipping: A Cross-Country Study,” Journal of Consumer Research, 20, 478-485.

Namasivayam, K. and Upneja, A. (2007), “Employee Preferences for Tipping Systems,” Journal of Foodservice Business Research, 10, 93-107.

Newman, D. (2007), “Cruise Line Tipping Policies,” (May 24, 2007), Available at: http://www.cruisecritic.com/articles.cfm?ID=265.

Parise, M. (1987), “Optional Tipping Has Seen Its Day,” Nation’s Restaurant News, March 9, p. F50.

Payscale (2009), “How’s Your Tipping Etiquette? Check Out Payscale’s Tipping Chart.” Available online at: http://www.payscale.com/tipping-chart (accessed Aug. 18, 2009).

Podsakoff, P.M., MacKenzie, S.B., Lee, J.Y. and Podsakoff, N.P. (2003). “Common Method Biases in Behavioral Research: A Critical Review of the Literature and Recommended Remedies.” Journal of Applied Psychology, 88, 879-903.

Powell, I. Montgomery, M. and Cosgrove, J. (1994), “Compensation Structure and Establishment Quit and Fire Rates,” Industrial Relations, 33, 229-248. 
Richardson, H.A., Simmering, M.J. and Sturman, M.C. (2009), “A Tale of Three Perspectives: Examining Post-Hoc Statistical Techniques for Detection and Correction of Common Method Variance,” Organizational Research Methods, 12, 762-800.

Salamin, A. and Hom, P.W. (2005), "In Search of The Elusive U-Shaped Performance-Turnover Relationship: Are High Performing Swiss Bankers More Liable to Quit?,” Journal of Applied Psychology, 90, 1204-1216.

Schotter, A. (2000), “Moral Hazard and Adverse Selection: Information Market Failures,” Micro-Economics: A Modern Approach, $3^{\text {rd }}$ Ed.. New York: Addison Wesley.

Seiter, J.S. (2007), “Ingratiation and Gratuity: The Effect of Complementing Customers on Tipping Behavior in Restaurants,” Journal of Applied Social Psychology, 37, 478-485.

Spector, P.E. (2006). “Method Variance in Organizational Research: Truth or Urban Legend?” Organizational Research Methods, 9, 221-232.

Stajkovic, A.D. and Luthans, F. (2001), “Differential Effects of Incentive Motivators on Work Performance,” Academy of Management Journal, 4, 580-590.

Star, N. (1988), The International Guide to Tipping, New York: Berkley Books.

Strohmetz, D.B., Rind, B., Fisher, R. and Lynn, M. (2002), “Sweetening The Til: The Use of Candy to Increase Restaurant Tipping,” Journal of Applied Social Psychology, 32, 300-309.

Sturman, M. C., \& Trevor, C. O. (2001). “The Implications of Linking the Dynamic Performance and Turnover Literatures.” Journal of Applied Psychology, 86, 684-696.

Tett, R.P. and Meyer, J.P. (1993), “Job Satisfaction, Organizational Commitment, Turnover Intention, and Turnover: Path Analysis Based on Meta-Analytic Findings,” Personnel Psychology, 46, 259-293. 
Trevor, C.O., Gerhart, B. and Boudreau, J.W. (1997). "Voluntary Turnover and Job Performance: Curvilinearity and the Moderating Influences of Salary Growth and Promotions.” Journal of Applied Psychology, 82(1), 44-61.

Tse, A. (2003), “Tipping Behavior: A Disconfirmation of Expectation Perspective,” International Journal of Hospitality Management, 22, 461-467.

Williams, L.J., Cote J.A. and Buckley, M.R. (1989). "Lack of Method Variance in SelfReported Affect and Perceptiosn at Work: Reality or Artifact?” Journal of Applied Psychology, 74, 462-468.

Vroom, V.H. (1964), Work and Motivation, New York: John Wiley. 
TABLE 1. Descriptive statistics and zero-order correlations between items.

\begin{tabular}{|c|c|c|c|c|c|c|c|c|c|c|c|}
\hline Variable & $\mathrm{N}$ & Mean & $\begin{array}{l}\text { Standard } \\
\text { Deviation }\end{array}$ & Tenure & Tips & $\begin{array}{l}\text { Perceived } \\
\text { service-tip } \\
\text { contingency }\end{array}$ & $\begin{array}{l}\text { Service } \\
\text { attitude }\end{array}$ & Sex & Age & White & Married \\
\hline $\begin{array}{l}\text { Attraction to } \\
\text { tipped } \\
\text { service jobs }\end{array}$ & 337 & 4.61 & 2.16 & $.19 * *$ & $.25 * *$ & $.24 * *$ & $.14^{* *}$ & $-.11 *$ & $.12^{*}$ & .06 & -.01 \\
\hline $\begin{array}{l}\text { Tenure as a } \\
\text { server (in } \\
\text { years) }\end{array}$ & 335 & 5.24 & 5.52 & & $.26 * *$ & $.12^{*}$ & $.13^{*}$ & $-.12 *$ & $.76^{* *}$ & .09 & $.33 * *$ \\
\hline $\begin{array}{l}\text { Comparative } \\
\text { tips }\end{array}$ & 335 & 4.79 & 1.10 & & & $.31 * *$ & $.18^{* *}$ & -.04 & $.16^{* *}$ & .07 & .08 \\
\hline $\begin{array}{l}\text { Perceived } \\
\text { service-tip } \\
\text { contingency }\end{array}$ & 335 & 5.17 & 1.47 & & & & $.43^{* *}$ & -.03 & .01 & .06 & .04 \\
\hline $\begin{array}{l}\text { Service } \\
\text { attitude }\end{array}$ & 336 & 5.04 & .68 & & & & & -.02 & .08 & .06 & .02 \\
\hline Sex & 335 & .76 & .43 & & & & & & $-.20 * *$ & .08 & .04 \\
\hline Age & 334 & 24.58 & 6.66 & & & & & & & .04 & $.36^{* *}$ \\
\hline White & 322 & .91 & .29 & & & & & & & & .00 \\
\hline Married & 335 & .14 & .35 & & & & & & & & \\
\hline
\end{tabular}

$* \mathrm{p}<.05, * * \mathrm{p}<.01$ 
TABLE 2. Regression coefficients (and standard errors) from analyses predicting attraction to tipped jobs and testing Hypotheses 1 and 2.

\begin{tabular}{lll}
\hline Dependent Variable & $\begin{array}{l}\text { Attraction to Tipped } \\
\text { Jobs }\end{array}$ & $\begin{array}{l}\text { Attraction to Tipped } \\
\text { Jobs }\end{array}$ \\
\hline Intercept & 2.03 & $7.17^{* *}$ \\
Sex & $(1.05)$ & $(2.40)$ \\
& -.55 & $-.58^{*}$ \\
Age & $.29)$ & $(.28)$ \\
& .03 & .04 \\
White & $(.02)$ & $(.02)$ \\
& .30 & .26 \\
Married & $(.42)$ & $(.41)$ \\
& -.28 & -.42 \\
Service Attitude & $(.38)$ & $(.36)$ \\
(SA) & $.40^{*}$ & $-1.04 *$ \\
& $(.17)$ & $(.47)$ \\
Perceived Service- & & -.83 \\
Tip Contingency & & $(.49)$ \\
(PSTC) & & $.24 *$ \\
SA x PSTC & & $(.10)$ \\
$\mathrm{R}^{2}$ & .04 & .12 \\
$\mathrm{n}$ & 318 & 317 \\
\hline \multirow{2}{*}{$\mathrm{p}<.05, * * \mathrm{p}<.01, * * * \mathrm{p}<.001$} &
\end{tabular}


TABLE 3. Regression coefficients (and standard errors) from analyses predicting tip income and tenure as a server and testing Hypotheses 3 to 5.

\begin{tabular}{llll}
\hline Dependent Variable & Tip Income & Tenure as a Server & Tenure as a Server \\
\hline Intercept & $2.58^{* * *}$ & $-10.33^{* * *}$ & $-11.23^{* * *}$ \\
& $(.53)$ & $(1.05)$ & $(1.17)$ \\
Sex & -.02 & .40 & .17 \\
& $(.14)$ & $(.43)$ & $(.42)$ \\
Age & $.02^{*}$ & $.53^{* * *}$ & $.50^{* * *}$ \\
& $(.01)$ & $(.03)$ & $(.03)$ \\
White & .09 & .68 & .70 \\
& $(.21)$ & $(.63)$ & $(.60)$ \\
Married & .06 & .51 & .44 \\
& $(.19)$ & $(.56)$ & $(.54)$ \\
Service Attitude (SA) & $.31^{* * *}$ & & \\
& $(.09)$ & & \\
Attraction to Tipped & & $.28^{* *}$ & \\
Jobs & & $(.08)$ & $.64^{* * *}$ \\
Tip Income & & & $(.16)$ \\
& & & .56 \\
$\mathrm{R}^{2}$ & .07 & .57 & 311 \\
$\mathrm{n}$ & 316 & 313 & \\
\hline
\end{tabular}

${ }^{*} \mathrm{p}<.05,{ }^{* *} \mathrm{p}<.01,{ }^{* * *} \mathrm{p}<.001$ 
TABLE 4. Regression coefficients (and standard errors) from analyses predicting tenure as server and testing Hypothesis 6.

\begin{tabular}{lll}
\hline Dependent Variable & Tenure as a Server & Tenure as a Server \\
\hline Intercept & $-11.61^{* * *}$ & $-12.66^{* * *}$ \\
& $(1.58)$ & $(1.57)$ \\
Sex & .26 & .29 \\
& $(.44)$ & $(.42)$ \\
Age & $.71^{* * *}$ & $.49^{* * *}$ \\
& $(.03)$ & $(.03)$ \\
White & .45 & .62 \\
& $(.63)$ & $(.60)$ \\
Married & .45 & .52 \\
& $(.56)$ & $(.54)$ \\
Service Attitude (SA) & $.51^{*}$ & .25 \\
& $(.26)$ & $(.25)$ \\
Attraction to Tipped & & $.20^{*}$ \\
Jobs & & $(.08)$ \\
Tip Income & & $.50^{* *}$ \\
& & $(.17)$ \\
$\mathrm{R}^{2}$ & .56 & .57 \\
$\mathrm{n}$ & 313 & 311 \\
\hline
\end{tabular}

${ }^{*} \mathrm{p}<.05,{ }^{* *} \mathrm{p}<.01,{ }^{* * *} \mathrm{p}<.001$ 


\section{Figure 1}

The Selective Attraction and Retention Effects of Voluntary Tipping

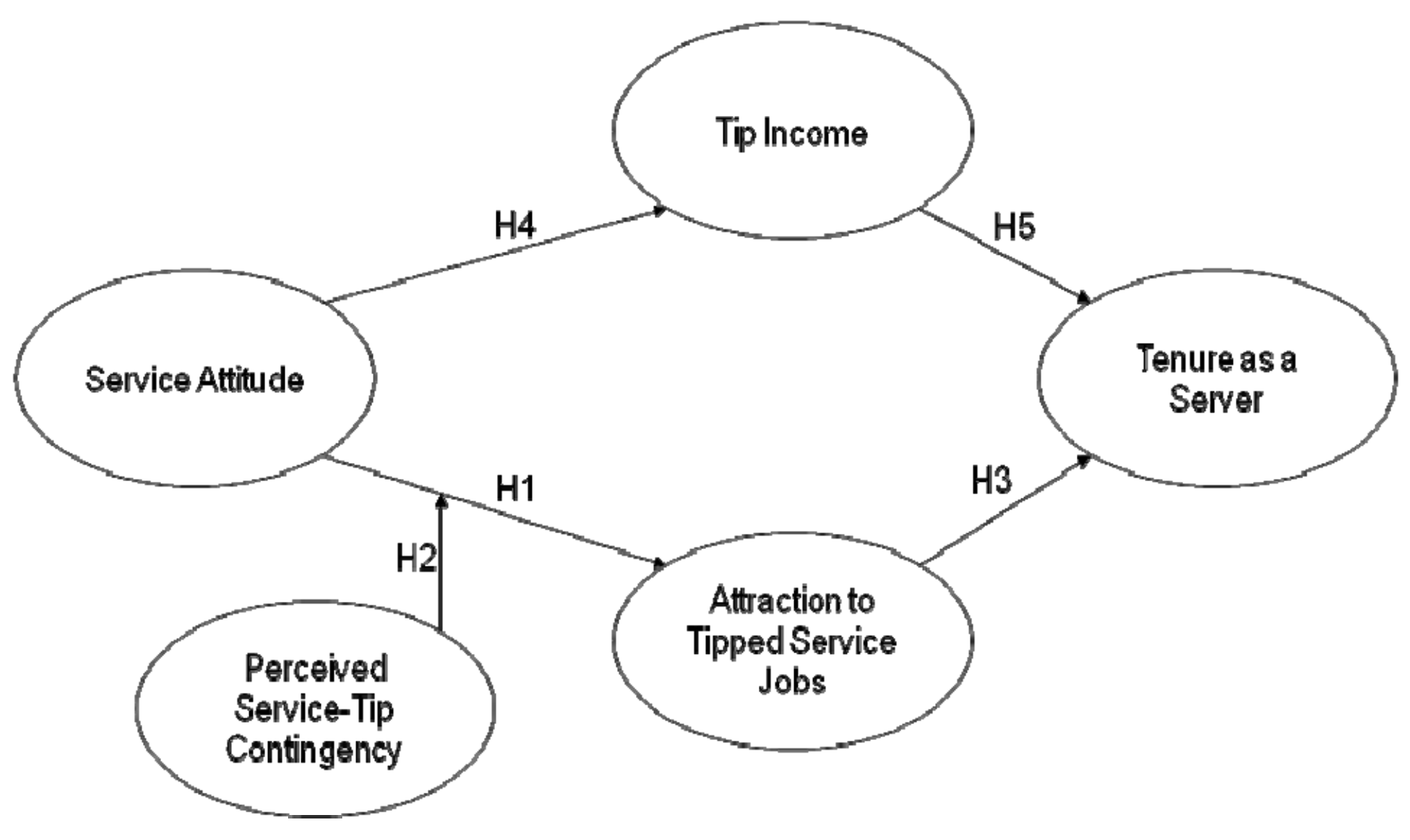

